\title{
Atividade elicitora de fitoalexinas em Soja e Sorgo por extratos e tinturas de espécies medicinais
}

\author{
MATIELLO, J.; BONALDO, S.M.* \\ Universidade Federal de Mato Grosso, Instituto de Ciências Agrárias e Ambientais (ICAA) - UFMT- Campus \\ de Sinop, Av. Alexandre Ferronato, no. 1.200 Reserva 35 - Distrito Industrial SINOP - MT - CEP: 78.557-267, \\ Sinop, Brasil. *sbonaldo@ufmt.br
}

\begin{abstract}
RESUMO - A verificação da capacidade indutora de fitoalexinas a partir de extratos e tinturas de espécies vegetais pode representar uma forma potencial de controle de doenças em plantas cultivadas. O objetivo foi verificar a capacidade de indução de fitoalexinas em cotilédones de Soja e mesocótilos de Sorgo a partir de extratos brutos aquosos (EBAs) e tinturas de espécies medicinais. As espécies utilizadas foram as plantas medicinais Arruda (Ruta graveolens), Manjerona (Origanum majorana) e Carqueja (Baccharis trimera). Os resultados obtidos mostraram que os EBAs são eficientes na indução de fitoalexinas em cotilédones de Soja. Em mesocótilos de Sorgo os EBAs das plantas medicinais Carqueja e Manjerona induzem a produção de fitoalexinas em concentrações elevadas (15, 20, 25 e 50\%). As tinturas são capazes de induzir a produção de fitoalexinas em cotilédones de Soja nas concentrações de 10 e 15\%, porém, não são capazes de induzir acúmulo de fitoalexinas em mesocótilos de Sorgo.
\end{abstract}

Palavras-Chave: Gliceolina, deoxiantocianidinas, extrato bruto aquoso, tintura.

\begin{abstract}
Eliciting activity of phytoalexins in Soybean and Sorghum by extracts and tinctures of medicinal species- The verification of the capacity to induce phytoalexins from the biological activity of plant species may represent a potential way to control diseases in crops. This research studied the induction of phytoalexins in cotyledons of Soybean and Sorghum mesocotyles from crude aqueous extracts (CAEs) and tinctures of plants of medicinal and forest species. The species used were the medicinal plants Ruta graveolens, Baccharis trimera and Origanum majorana. The results showed that CAEs are efficient in the induction of phytoalexins in cotyledons of soybean. , while CAEs of medicinal plants Baccharis trimera and Origanum majorana induce phytoalexin production in high concentrations (15, 20, 25 and 50\%). Tinctures are able of inducing the production of phytoalexin in concentrations of 10 and $15 \%$ in Soybean cotyledons; however, they are not able to induce the accumulation of phytoalexins in Sorghum mesocotyles.
\end{abstract}

Keywords: Gliceollin, deoxyanthocyanidin, crude aqueous extract, tincture.

\section{INTRODUÇÃO}

A agricultura tem aumentado a sua capacidade produtiva, bem como o uso de produtos tóxicos, principalmente de pesticidas, para o controle de doenças de plantas. Porém, o controle químico tradicional depara-se com o surgimento de patógenos resistentes às substâncias químicas utilizadas (Pascholati, 1998) incentivando a busca por produtos com métodos alternativos de ação, para diminuir os danos causados ao ambiente e aos seres vivos.
O extrato bruto aquoso ou o óleo essencial de plantas medicinais têm mostrado potencial no controle de fitopatógenos, tanto por sua ação fungitóxica direta, inibindo o crescimento micelial e a germinação de esporos (Soares et al.,1998; Rodrigues et al., 2006; Aitako et al., 2008; SchwanEstrada et al., 2008), quanto pela capacidade em induzir o acúmulo de fitoalexinas em Soja e Sorgo (Bonaldo et al.,1999, 2004; Rodrigues et al., 2007; Franzener et al., 2007; Meinerz et al., 2008), o

Recebido para publicação em 09/09/2011

Aceito para publicação em 20/02/2013

Rev. Bras. PI. Med., Campinas, v.15, n.4, p.541-550, 2013. 
que indica, portanto, a presença de composto ou molécula com característica de elicitores.

Dentre as plantas medicinais com ação fungitóxica estudadas, destacam-se a Arruda $(R$. graveolens), Manjerona (O. majorana) e Carqueja ( $B$. trimera), porém, há necessidade de aprofundamento dos estudos destas plantas medicinais na atividade elicitora de fitoalexinas em Sorgo e Soja. A Arruda (R. graveolens) é originária da Europa meridional e cultivada em vários países como planta medicinal. A Arruda é pertencente à família Rutaceae, subartusto perene, rizomatoso, de caule ereto, lenhoso na parte inferior e pouco ramificado; muito utilizada na medicina popular na forma de chá como medicação caseira no tratamento de desordens menstruais, inflamações na pele, dor de ouvido, dor de dente, febre, câimbras, doenças do fígado e verminoses (Lorenzi \& Matos, 2008). A Carqueja (B. trimera) é uma planta originária do Brasil, pertencente à família das Compositae, arbusto perene de pequeno porte, de aproximadamente $1,2 \mathrm{~m}$, possui ramos trifoliados e inflorescências em capítulo. Sua propagação pode ser via sementes ou estacas, deve ser plantada em solos com bom teor de umidade (Martins et al., 2003). Esta planta é muito utilizada principalmente para problemas hepáticos, contra disfunções estomacais e intestinais (Lorenzi \& Matos, 2008). A Manjerona (O. majorana) é originaria do Nordeste da África, Oriente Médio até a Índia, pertencendo à família das Lamiaceae, considerada uma erva ou planta perene. Refere-se a uma planta herbácea a qual atinge cerca de $20-30 \mathrm{~cm}$, possui caule lenhoso na base, quadrangular formando toceiras, suas folhas são pequenas, opostas, pecioladas, verdeacizentadas. Suas flores rosadas são dispostas em espigas axilares. As sementes são escuras pequenas e ovais (Couto, 2006).

O fracionamento dos metabólitos secundários dessas plantas, bem como a determinação da atividade biológica dessas moléculas com respeito a atividade elicitora ou antimicrobiana, poderá contribuir para a aquisição de maiores conhecimentos que reforcem sua possível utilização como método alternativo de controle de doenças de plantas (Stangarlin et al.,1999). Dentre as atividades biológicas estudadas destacam-se as fitoalexinas, pois segundo Stangarlin et al. (1999), bioensaios com cotilédones de Soja e com mesocótilos estiolados de Sorgo são ferramentas importantes para se testar o efeito elicitor de um tratamento.

As fitoalexinas são compostos antimicrobianos de baixa massa molecular, sintetizadas e acumuladas nas plantas após estresses físicos, químicos ou biológicos, como o contato com microorganismos, e seu papel na resistência a patógenos é amplamente estudado, sendo capaz de reduzir ou impedir a atividade de agentes patogênicos (Braga, 2008).

Para Hammerschmidt (1999), as evidências do papel das fitoalexinas na resistência a doenças de plantas incluem: acúmulo destas substâncias em resposta ao desenvolvimento do patógeno, correlação positiva da velocidade de produção de fitoalexinas na presença do patógeno, associação do rápido acúmulo de fitoalexinas com genes de resistência que restringem o desenvolvimento do patógeno e aumento na resistência do tecido da planta pelo estímulo na produção de fitoalexinas antes da inoculação.

Assim, o presente trabalho objetivou verificar a capacidade de produção de fitoalexinas em cotilédones de Soja e mesocótilos de Sorgo, a partir de extratos brutos aquosos (EBA) e tinturas, obtidas das plantas medicinais Arruda (Ruta graveolens), Carqueja (Baccharis trimera) e Manjerona (Origanum majorana).

\section{MATERIAL E MÉTODOS}

Os experimentos foram realizados no Laboratório de Microbiologia/Fitopatologia da Universidade Federal de Mato Grosso, Campus Sinop.

\section{Plantas medicinais}

Para o desenvolvimento do trabalho foram utilizadas as plantas medicinais Arruda ( $R$. graveolens L.) _Manjerona (O. majorana L.) e Carqueja (B. trimera (Less.) DC.).

\section{Extrato bruto aquoso}

Os extratos brutos aquosos com 1, 5, 10, $15,20,25$ e $50 \%$ de material vegetal foram obtidos conforme Bonaldo et al. (2004). Para tanto, folhas foram coletadas, lavadas em água destilada e trituradas em liquidificador com água destilada esterilizada. Este extrato bruto foi então filtrado em gaze e em papel de filtro Whatman n. 41 e utilizado nos bioensaios de fitoalexinas em Sorgo e Soja.

\section{Tinturas}

Folhas frescas foram coletadas e trituradas em liquidificador com álcool comercial hidratado na proporção de $250 \mathrm{~g}$ de material vegetal em $1000 \mathrm{~mL}$ de álcool. As folhas permaneceram em maceração por 15 dias e os frascos foram agitados, diariamente, durante este período (Farmacopéia Brasileira, 1988). O extrato resultante foi filtrado e, o volume inicial reposto com o álcool e armazenado em frasco âmbar, em temperatura ambiente. As tinturas foram diluídas nas concentrações de $0,5 \%, 1 \%, 5 \%, 10 \%$ e $15 \%$ para serem utilizadas nos bioensaios de produção de fitoalexinas em mesocótilos de Sorgo 
e cotilédones de Soja.

\section{Bioensaio para produção de fitoalexinas em cotilédones de Soja}

Foram utilizadas sementes de Soja (Glycine max L.) da cultivar MONSOY 8866 para os ensaios com extratos bruto aquosos e a cultivar V-MAX para os ensaios com as tinturas, que foram plantadas em areia esterilizada e mantidas em condições ambientais. Após nove dias, os cotilédones foram destacados das plântulas, lavados em água destilada, enxugados e cortados em secção aproximada de $1 \mathrm{~mm}$ de espessura e 6 $\mathrm{mm}$ de diâmetro a partir da superfície inferior. Cinco cotilédones foram colocados em placa de Petri com papel de filtro umedecido com água destilada estéril. Foi aplicada sobre cada cotilédone uma alíquota de $75 \mu \mathrm{L}$ do extrato bruto ou da tintura, obtidos conforme descrito anteriormente. Cada tratamento foi constituído de cinco repetições. As placas de Petri foram mantidas a $25^{\circ} \mathrm{C}$ no escuro por 20 horas, e em seguida, os cotilédones foram transferidos para tubos de ensaio contendo $15 \mathrm{~mL}$ de água destilada esterilizada e deixados em agitação por uma hora para extração da fitoalexina formada. A fitoalexina induzida nos cotilédones de Soja foi a gliceolina e a absorbância (ABS ${ }_{285}$ ) foi determinada a $285 \mathrm{~nm}$ (Ziegler \& Pontzen,1982).

O delineamento experimental utilizado, no experimento com extrato bruto aquoso, foi o inteiramente casualizado (DIC) com cinco repetições e 24 tratamentos, com esquema fatorial $8 \times 3$, cujos fatores foram: oito concentrações do extrato aquoso $(0,1,5,10,15,20$ e $25 \%)$, e três espécies medicinais. A análise estatística foi realizada com o programa ESTAT Versão 2.0 da UNESP de Botucatu, e as médias do fator qualitativo (plantas medicinais) foram submetidas à análise de variância (ANOVA), aplicando-se o teste $F$, no nível de $5 \%$ de probabilidade, e, posteriormente, as médias foram comparadas pelo teste de Tukey a $1 \%$ de significância. O estudo do fator quantitativo (concentrações) foi realizado por meio de análise de regressão. A unidade experimental foi constituída por uma placa de Petri com cinco cotilédones.

No experimento com tinturas, o delineamento experimental utilizado, foi o inteiramente casualizado (DIC) com cinco repetições e 18 tratamentos, com esquema fatorial $6 \times 3$, cujos fatores foram: seis concentrações de tintura $(0,0,5,1,5,10$ e $15 \% \%)$, e três plantas medicinais.

\section{Bioensaio para produção de fitoalexinas em mesocótilos de Sorgo \\ O bioensaio de fitoalexinas em Sorgo foi}

realizado conforme metodologias de Nicholson et al. (1988) e Wulff (1997). Sementes de Sorgo (Sorghum bicolor L.), cultivar BRS-310, foram desinfetadas em hipoclorito de sódio 1\% (15 min), lavadas em água destilada e embebidas em água sob temperatura ambiente por seis horas. Após este período foram enroladas em folhas de papel de germinação umedecidas e incubadas em escuro à $28^{\circ} \mathrm{C}$ por quatro dias. As plântulas formadas foram expostas a luz por quatro horas para paralisar a elongação dos mesocótilos.

No teste de produção de fitoalexinas, os mesocótilos foram excisados $0,5 \mathrm{~cm}$ acima do nó escutelar e colocados em tubos de ensaio (1,2 x 10cm; sendo 3 mesocótilos/tubo); contendo uma alíquota dos EBAs ou das tinturas, em cinco repetições para cada concentração dos EBAs e das tinturas. Estes tubos foram mantidos em câmara úmida, a $25^{\circ} \mathrm{C}$ sob luz fluorescente, por 60 horas Wulff (1997). Após esse período, os mesocótilos foram retirados dos tubos, secos e os $5 \mathrm{~mm}$ basais de cada mesocótilo foram excisados e descartados. A porção superior $(2,5 \mathrm{~cm})$ foi pesada, cortada em pequenos segmentos e colocadas em tubos para microcentrífuga contendo $1,40 \mathrm{~mL}$ de metanol $80 \%$ acidificado $(0,1 \% \mathrm{HCl}$; v/v). Os mesocótilos cortados foram mantidos a $4^{\circ} \mathrm{C}$ no metanol por 96 horas para extração dos pigmentos. A fitoalexina induzida nos mesocótilos de Sorgo foi a deoxiantocianidina e a absorbância foi determinada a 480nm por grama de peso fresco (ABS ${ }_{480}$ /g.p.f.).

A água destilada esterilizada foi utilizada como controle negativo, não atuando como indutor, sendo caracterizada como a concentração de $0 \%$.

O delineamento experimental utilizado, no experimento com extrato bruto aquoso, foi o inteiramente casualizado (DIC) com cinco repetições e 24 tratamentos, com esquema fatorial $8 \times 3$, cujos fatores foram: oito concentrações do extrato aquoso $(0,1,5,10,15,20$ e $25 \%)$, e três espécies medicinais. A análise estatística foi realizada com o programa ESTAT Versão 2.0 da UNESP de Botucatu, onde as médias do fator qualitativo (plantas medicinais) foram submetidas à análise de variância (ANOVA), aplicando-se o teste $F$, no nível de $5 \%$ de probabilidade, e, posteriormente, as médias foram comparadas pelo teste de Tukey a $1 \%$ de significância. $\mathrm{O}$ estudo do fator quantitativo (concentrações) foi realizado por meio de análise de regressão. A unidade experimental foi constituída por um tubo de microcentrífuga com três mesocótilos.

No experimento com tinturas, o delineamento experimental utilizado, foi o inteiramente casualizado (DIC) com cinco repetições e 18 tratamentos, com esquema fatorial $6 \times 3$, cujos fatores foram: seis concentrações de tintura $(0,0,5,1,5,10$ e 15\%), e três plantas medicinais. 


\section{RESULTADOS E DISCUSSÃO}

Síntese de fitoalexinas em cotilédones de Soja por extrato bruto aquoso (EBA) de plantas medicinais

Os EBAs de plantas medicinais demonstraram capacidade de indução de fitoalexinas semelhantes em cotilédones de Soja (Figura 1), apesar disso houve diferença significativa entre as espécies testadas, conforme observado na Tabela 1.

O EBA de Carqueja proporcionou maior síntese de fitoalexinas em Soja em todas as concentrações com maior valor de indução na concentração de $50 \%$. Extrato bruto aquoso de Carqueja diferiu estatisticamente apenas do EBA de Arruda, nas concentrações de 5\%,15\%, 20\%, $25 \%$ e $50 \%$. O EBA de Manjerona teve sua maior indução na concentração de 50\%, mas não diferiu estatisticamente de Carqueja e Arruda em nenhuma concentração. O EBA de Arruda apresentou maior indução do que o EBA de Manjerona na concentração de $1 \%$, porém nas concentrações de

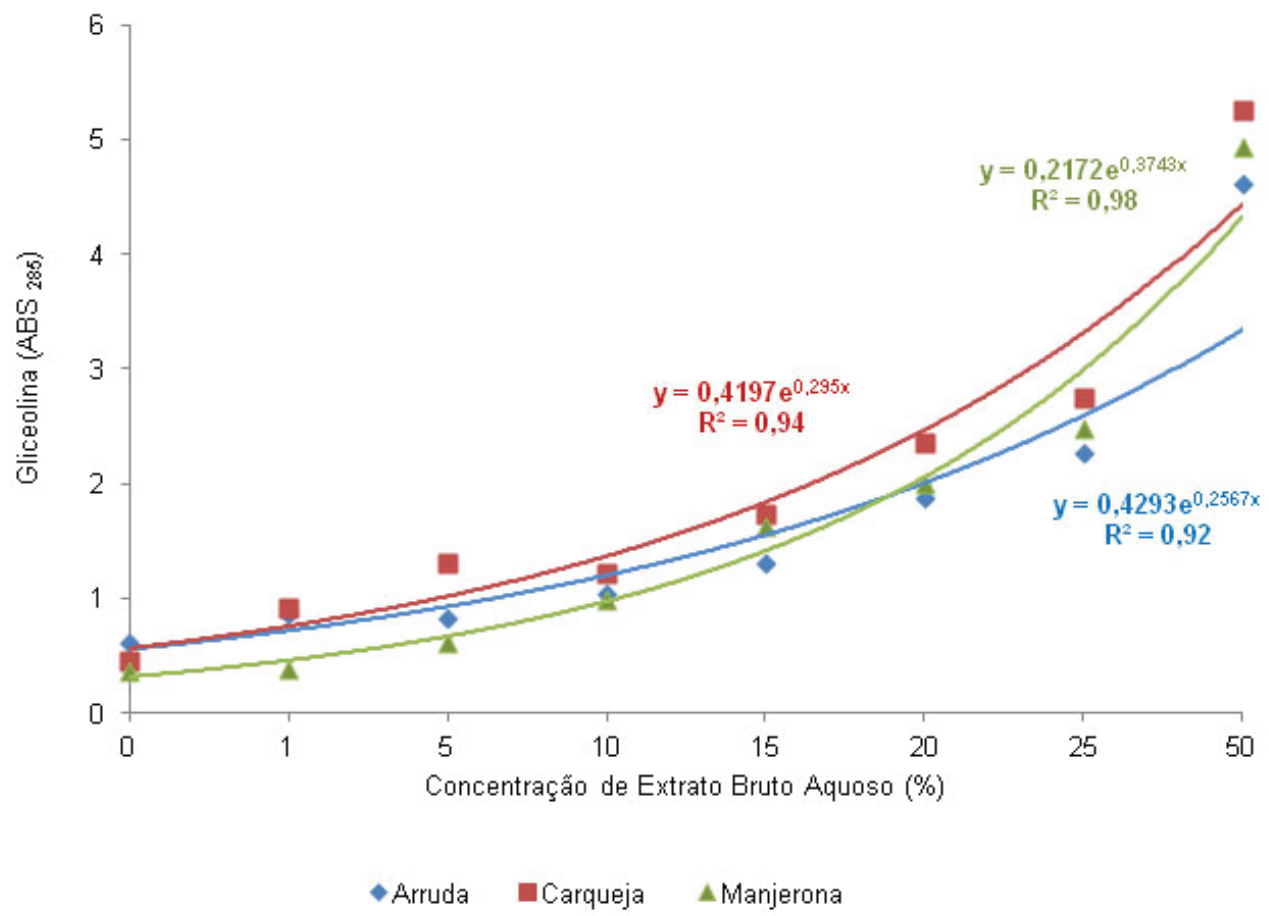

FIGURA 1. Indução de gliceolina em cotilédones de soja, em diferentes concentrações de extrato bruto aquoso das plantas medicinais: arruda (Ruta graveolens), carqueja (Baccharis trimera) e manjerona (Origanum majorana).

TABELA 1. Médias da indução de gliceolina em diferentes concentrações de extrato bruto aquoso das plantas medicinais: arruda (Ruta graveolens), carqueja (Baccharis trimera) e manjerona (Origanum majorana).

\begin{tabular}{cccc}
\hline \multirow{2}{*}{ Concentração extrato bruto aquoso (\%) } & \multicolumn{3}{c}{ Espécies medicinais } \\
\cline { 2 - 4 } & Arruda & Carqueja & Manjerona \\
\hline 0 & $0,6220^{1} \mathrm{a}$ & $0,4484 \mathrm{a}$ & $0,3712 \mathrm{a}$ \\
1 & $0,8632 \mathrm{a}$ & $0,9224 \mathrm{a}$ & $0,3888 \mathrm{~b}$ \\
5 & $0,8292 \mathrm{~b}$ & $1,3158 \mathrm{a}$ & $0,6110 \mathrm{~b}$ \\
10 & $1,0402 \mathrm{a}$ & $1,2238 \mathrm{a}$ & $0,9978 \mathrm{a}$ \\
15 & $1,3012 \mathrm{~b}$ & $1,7448 \mathrm{a}$ & $1,6330 \mathrm{ab}$ \\
20 & $1,8758 \mathrm{~b}$ & $2,3512 \mathrm{a}$ & $2,0008 \mathrm{ab}$ \\
25 & $2,2782 \mathrm{~b}$ & $2,7468 \mathrm{a}$ & $2,4884 \mathrm{ab}$ \\
50 & $4,6200 \mathrm{~b}$ & $5,2530 \mathrm{a}$ & $4,9344 \mathrm{ab}$ \\
\hline
\end{tabular}

\section{E.P. $(\%)=0,2579$}

Médias seguidas da mesma letra minúscula na linha não diferem entre si pelo teste de Tukey a 1\% de significância. ${ }^{1}$ Valor de absorbância (285 nanômetros para gliceolina). 
$15 \%, 20 \%$, $25 \%$ e $50 \%$, houve menor eficiência, quando comparado com os EBAs de Carqueja e Manjerona (Figura 1).

Mazaro et al. (2008) trabalhando com derivados de extrato alcoólico, infusão, maceração e decocção, obtidos de folhas de pitangueira, nas concentrações de 0,$1 ; 1 ; 10$ e $40 \%$, observaram que os preparados de pitangueira apresentaram capacidade de indução das fitoalexinas gliceolinas em cotilédones de Soja, respondendo ao aumento das concentrações dos preparados. Estes mesmos autores observaram que o efeito da indução foi caracterizado com o aumento das concentrações dos preparados, sendo que as que apresentaram maior resposta foram, para extrato alcoólico, as concentrações de dez e $40 \%$; infusão a concentração de $40 \%$, decocção a concentração de $40 \%$ e maceração as concentrações de10 e $40 \%$. Rodrigues et al. (2007), relataram a presença de compostos elicitores nas concentrações de 1, 5, 10, 15,20 e $25 \%$ de extrato bruto aquoso de gengibre (Zingiber officinalis), observada pela indução de fitoalexinas em Soja, que ocorreu de maneira dose dependente. Os resultados destes autores colaboram com o observado no presente trabalho, com maior produção de fitoalexinas nas maiores concentrações do extrato bruto aquoso.

Os resultados obtidos foram semelhantes aos obtidos por Stangarlin et al. (1999), quando trabalharam com extratos de plantas medicinais e observaram que os extratos de pitanga, cânfora, poejo, romã e cardo santo foram os mais efetivos em induzir o acúmulo de gliceolina em cotilédones de Soja.

Em diversos trabalhos têm sido relatado à eficácia de extratos vegetais no controle de doenças como em bioensaios realizados por Schwan-Estrada et al. (2000). Estes autores relataram que os extratos brutos de romã, erva cidreira, Manjerona, babosa e orégano foram os mais efetivos, entre as plantas medicinais testadas, em induzir o acúmulo de um complexo de pigmentos.

Síntese de fitoalexinas em mesocótilos de Sorgo por extrato bruto aquoso de espécies medicinais

Para os EBAs de espécies medicinais, na indução de fitoalexinas em mesocótilos de Sorgo, observa-se que houve diferença significativa em relação aos EBAs (Tabela 2; Figura 2) e concentrações utilizadas. Na análise de regressão, foi possível ajustar as linhas de tendência para os EBAs de Carqueja e Manjerona, que obtiveram o valor do coeficiente de variação de 0,811 e 0,74 respectivamente. Porém, não foi possível ajustar linha de tendência para os dados de indução de fitoalexinas do EBA de Arruda (Figura 2).

O EBA de Manjerona proporcionou as suas melhores induções de fitoalexinas nas concentrações de $15 \%, 20 \%$, 25\% e 50\%. Porém, entre os EBAs de plantas medicinais a maior síntese de fitoalexinas ocorreu na concentração de $50 \%$ do EBA de Carqueja. O EBA de Arruda não se mostrou eficiente, pois a média de deoxiantocianidinas no tratamento controle foi de $10.8362 \mathrm{ABS}_{480}$ /g.p.f. e não ocorreu diferença significativa no acúmulo de fitoalexinas entre o tratamento controle e as concentrações do EBA de Arruda em mesocótilos de Sorgo (Figura 2).

Com relação ao EBA de Carqueja observouse maior indução nas concentrações de $20 \%, 25 \%$ e $50 \%$ do extrato. As concentrações de $5 \%, 10 \%$

TABELA 2. Médias da indução de fitoalexinas em mesocótilos de sorgo em diferentes concentrações de extrato aquoso das plantas medicinais: arruda (Ruta graveolens), carqueja (Baccharis trimera) e manjerona (Origanum majorana).

\begin{tabular}{|c|c|c|c|c|c|c|}
\hline \multirow{2}{*}{ Concentração extrato bruto aquoso (\%) } & \multicolumn{6}{|c|}{ Espécies medicinais } \\
\hline & Arruda & & Carqueja & & Manjerona & \\
\hline 0 & $10,8362^{1}$ & a & 5,5076 & a & 7,1112 & a \\
\hline 1 & 9,5946 & a & 5,1228 & a & 4,4780 & a \\
\hline 5 & 12,706 & $\mathrm{ab}$ & 7,1520 & $\mathrm{~b}$ & 15,8498 & a \\
\hline 10 & 12,5888 & $\mathrm{~b}$ & 8,7680 & $b$ & 20,1462 & a \\
\hline 15 & 12,1086 & $\mathrm{~b}$ & 8,3816 & b & 29,7360 & a \\
\hline 20 & 4,0870 & c & 16,2284 & $b$ & 31,0046 & a \\
\hline 25 & 6,9342 & $\mathrm{~b}$ & 13,4210 & $\mathrm{~b}$ & 30,7042 & a \\
\hline 50 & 8,6778 & $\mathrm{c}$ & 47,8062 & $a$ & 29,8338 & $\mathrm{~b}$ \\
\hline
\end{tabular}

E.P. $(\%)=4,7849$

Médias seguidas da mesma letra minúscula na linha não diferem entre si pelo teste de Tukey a $1 \%$ de significância.

${ }^{1}$ Valor de absorbância (480 nanômetros para deoxiantocianidina) por grama de peso fresco.

Rev. Bras. PI. Med., Campinas, v.15, n.4, p.541-550, 2013. 


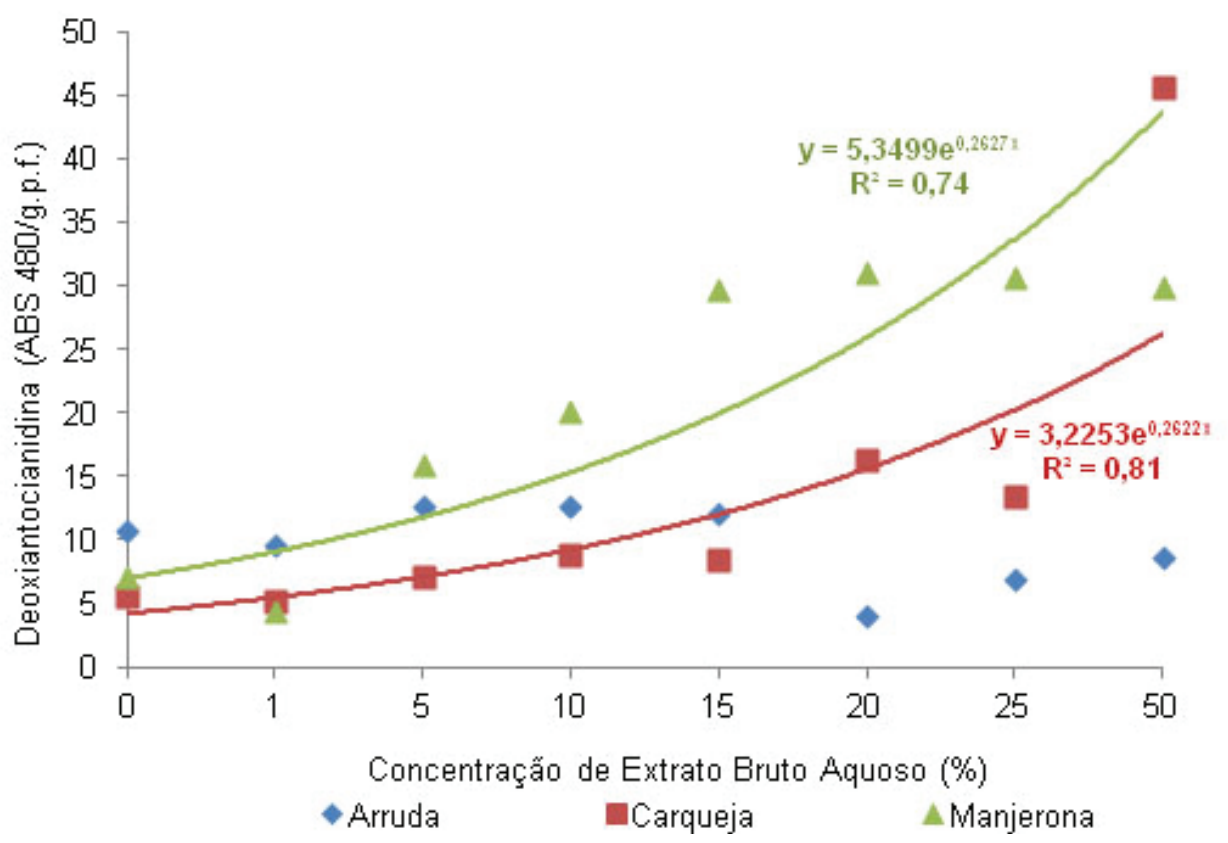

FIGURA 2. Produção de deoxiantocianidinas em mesocótilos de sorgo em diferentes concentrações de extrato bruto aquoso das plantas medicinais: arruda (Ruta graveolens), carqueja (Baccharis trimera) e manjerona (Origanum majorana).

e $15 \%$ apresentaram induções intermediárias, enquanto que a concentração de $1 \%$ apresentou menor eficiência que o controle negativo (água destilada esterilizada) na síntese de fitoalexinas. Este EBA apresentou na concentração de $50 \%$ a maior indução em mesocótilos de Sorgo em relação aos EBAs de Arruda e Manjerona (Tabela 2). Porém, as concentrações de $10 \%, 15 \%, 20 \%$, e $25 \%$ apresentaram induções intermediárias. 0 controle negativo superou a concentração de 1\%, e apenas as concentrações de $20 \%$ e $50 \%$ induziram fitoalexinas em relação ao controle negativo. Neste caso, é provável que a lesão mecânica (excisão dos mesocótilos) tenha induzido a produção da fitoalexina no controle negativo, pois as fitoalexinas podem ser produzidas pela planta em resposta a estresses físicos químicos ou biológicos (Cavalcanti et al., 2005).

$\mathrm{Na}$ concentração de $1 \%$ do EBA, a planta medicinal Arruda, proporcionou a maior indução de fitoalexinas em relação aos EBAs de Carqueja e Manjerona. Nas concentrações de 5\%, 10\% e 15\%, houve maior indução do que o EBA de Carqueja, entretanto, nas concentrações de $20 \%, 25 \%$ e $50 \%$, não houve indução quando comparado ao tratamento controle. Esse resultado pode indicar que o EBA de Arruda tem sua melhor capacidade indutora em mesocótilos de Sorgo em baixas concentrações; porém não houve diferença entre as concentrações de Arruda.

\section{Síntese de fitoalexinas em cotilédones de} Soja por tinturas

As tinturas de espécies medicinais apresentaram diferenças significativas na produção de fitoalexinas em cotilédones de Soja (Tabela 3). As concentrações mais baixas das tinturas, $0,5 \%$, $1 \%$ e $5 \%$ não induziram a síntese de gliceolina não diferindo do controle negativo (Figura 3).

Nas concentrações de 10\%, a tintura de Manjerona teve maior indução (1.5540 de média na $\mathrm{ABS}_{285}$ ) que a tintura de Arruda (1.2684 de média de $A B S_{285}$ ) não havendo diferença estatística entre as duas. Dentre as concentrações de $10 \%$ a tintura de Carqueja teve a menor indução, com 0.9074 de média de $\mathrm{ABS}_{285}$.

Porém, nas concentrações de $15 \%$ a tintura de Carqueja apresentou maior indução, com 2.6100 de média de $\mathrm{ABS}_{285}$, superando e diferindo estatisticamente das tinturas de Arruda e Manjerona, que na concentração de $15 \%$, tiveram 2.2426 e 1.9638 de média de $\mathrm{ABS}_{285}$ respectivamente.

A baixa indução de fitoalexinas em cotilédones de Soja pelas concentrações de $0,5 \%$, $1 \%$ e $5 \%$ das tinturas provavelmente é devido a diluição da tintura, visto que nas concentrações 
TABELA 3. Médias da indução de gliceolina em cotilédones de soja, em diferentes concentrações de tinturas das plantas medicinais: arruda (Ruta graveolens), carqueja (Baccharis trimera) e manjerona (Origanum majorana).

\begin{tabular}{cccc}
\hline Concentração extrato bruto aquoso (\%) & \multicolumn{3}{c}{ Espécies medicinais } \\
\cline { 2 - 4 } & Arruda & Carqueja & Manjerona \\
\hline 0 & $0,3644^{1} \mathrm{a}$ & $0,3434 \mathrm{a}$ & $0,3174 \mathrm{a}$ \\
0,5 & $0,3278 \mathrm{a}$ & $0,2758 \mathrm{a}$ & $0,3018 \mathrm{a}$ \\
1 & $0,3142 \mathrm{a}$ & $0,2918 \mathrm{a}$ & $0,1698 \mathrm{a}$ \\
5 & $0,2440 \mathrm{a}$ & $0,0908 \mathrm{a}$ & $0,1398 \mathrm{a}$ \\
10 & $1,2684 \mathrm{a}$ & $0,9074 \mathrm{~b}$ & $1,5540 \mathrm{a}$ \\
15 & $2,2426 \mathrm{~b}$ & $2,6100 \mathrm{a}$ & $1,9638 \mathrm{~b}$ \\
\hline
\end{tabular}

$$
\text { E.P. }(\%)=0,1928
$$

Médias seguidas da mesma letra maiúscula na coluna e mesma letra minúscula na linha não diferem entre si pelo teste de Tukey a $1 \%$ de significância.

'Valor de absorbância (285 nanômetros para gliceolina).

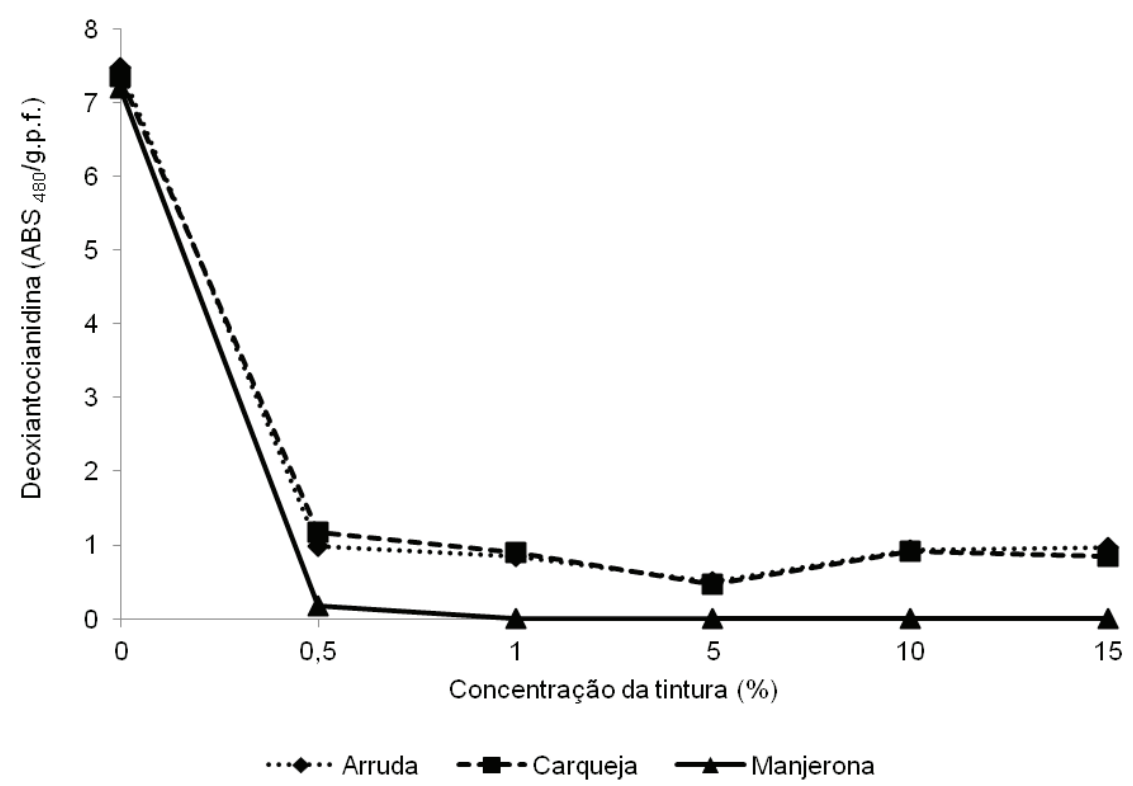

FIGURA 3. Produção de fitoalexinas (gliceolina) em cotilédones de soja em diferentes concentrações de tinturas das plantas medicinais: arruda (Ruta graveolens), carqueja (Baccharis trimera) e manjerona (Origanum majorana).

de $10 \%$ e $15 \%$ ocorreu indução. Ensaios futuros podem demonstrar o resultado da indução com concentrações acima de 15\% (Figura 3).

Estudos com tinturas de óleo essencial de capim-limão (Cymbopogon citratus) e tintura de alecrim (Rosmarinus officinalis) na indução de fitoalexina em hipocótilos de feijão (Phaseolus vulgaris) mostraram que as tinturas nas concentrações de $2,5 \%, 5 \%$ e $10 \%$ foram eficientes na indução de fitoalexinas na leguminosa (Oliveira et al., 2010).

\section{Síntese de fitoalexinas em mesocótilos de Sorgo por tinturas \\ O resultado da síntese de deoxiantocia-} nidinas, em mesocótilos de Sorgo, está representado na Tabela 4 e na Figura 4. Pode-se verificar que as tinturas de todas as plantas testadas não foram efetivas na indução de fitoalexinas em mesocótilos de Sorgo.

Para o teste com as tinturas de espécies medicinais a análise mostrou que a tintura de Manjerona não inibiu totalmente apenas na concentração de $0,5 \%$.

O que pode se visualizar com os resultados é que as tinturas inibiram a indução de fitoalexinas em mesocótilos de Sorgo. As tinturas de Arruda e Carqueja induziram uma pequena fração de fitoalexinas em todas as concentrações, mas muito baixas em comparação ao tratamento negativo, desse modo, não houve indução. A tintura de Manjerona não demonstrou nenhuma indução de 
TABELA 4. Médias da indução de fitoalexinas em mesocótilos de sorgo, em diferentes concentrações de tinturas das espécies medicinais: arruda (Ruta graveolens), carqueja (Baccharis trimera) e manjerona (Origanum majorana)

\begin{tabular}{cccc}
\hline Concentração extrato bruto aquoso (\%) & \multicolumn{3}{c}{ Espécies medicinais } \\
\cline { 2 - 4 } & Arruda & Carqueja & Manjerona \\
\hline 0 & 7,46701 & 7,3513 & 7,2010 \\
0,5 & 0,9836 & 1,1771 & 0,1717 \\
1 & 0,8387 & 0,9057 & 0,0000 \\
5 & 0,4988 & 0,4656 & 0,0000 \\
10 & 0,9250 & 0,9217 & 0,0000 \\
15 & 0,9652 & 0,8431 & 0,0000 \\
\hline E.P. $(\%)=0,1468$ & & \\
\hline
\end{tabular}

Não ocorreu diferença significativa entre espécies e concentrações pelo teste de Tukey. 1Valor de absorbância (480 nanômetros para deoxiantocianidina) por grama de peso fresco. Dados com o valor de zero foram transformados: $\operatorname{raiz}(x+$ alfa $)$, sendo alfa $=0,5$.

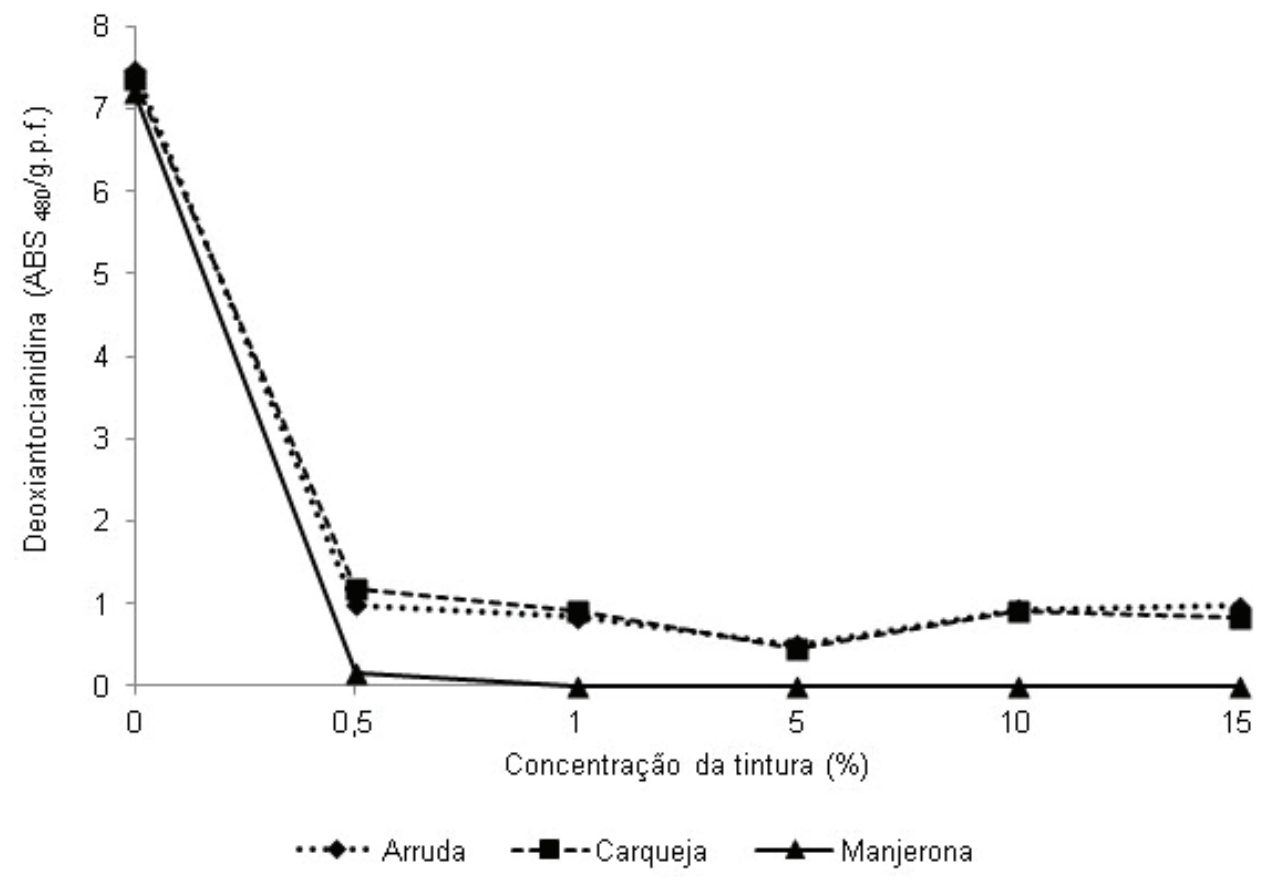

FIGURA 4. Produção de fitoalexinas em mesocótilos de sorgo em diferentes concentrações de tintura das plantas medicinais: arruda (Ruta graveolens), carqueja (Baccharis trimera) e manjerona (Origanum majorana).

fitoalexinas em quatro das cinco concentrações (1\%, $5 \%, 10 \%$ e $15 \%)$.

Verificou-se que houve fitotoxidez nos mesocótilos de Sorgo, com aspecto de murcha, após o período de incubação, principalmente nas maiores concentrações das tinturas testadas. A não produção de fitoalexinas em mesocótilos de Sorgo por estas tinturas deve ser analisada em estudos futuros; uma vez que as mesmas tinturas nas concentrações de 10 e 15\% induziram a produção de fitoalexinas em cotilédones de Soja. Ou seja, a fitotoxidez observada em Sorgo, pode estar relacionada com a sensibilidade do tecido da espécie hospedeira utilizada ao solvente.

\section{CONCLUSÃO}

Os EBA das plantas medicinais testadas são efetivos na indução de fitoalexinas em cotilédones de Soja.

O EBA da espécie Arruda é capaz de induzir a síntese de fitoalexinas em mesocótilos de Sorgo em baixas concentrações, enquanto que os EBAs das espécies Carqueja e Manjerona induzem em altas concentrações a síntese de fitoalexinas em mesocótilos de Sorgo.

As tinturas das espécies utilizadas apresentam potencial na indução de fitoalexinas em cotilédones de Soja nas concentrações de 10 e $15 \%$, enquanto que nas concentrações mais baixas 
a diluição da tintura inibiu a síntese de fitoalexinas.

As tinturas inibiram a síntese de fitoalexinas em mesocótilos de Sorgo e não apresentaram potencial como indutores.

\section{AGRADECIMENTO}

À FAPEMAT pelo apoio financeiro (PROCESSO No. 578323/2008) e ao CNPq/PIBIC pela concessão de bolsa de Iniciação Científica ao primeiro autor para execução deste trabalho.

\section{REFERÊNCIA}

BENNETT, R.; WALLSGROVE,R.M. Secondary metabolites in plant defense mechanisms. New Phytologist, v.127, p.617-633, 1994.

BETTIOL, W. (Ed.) Controle Biológico de Doenças de Plantas. Jaguariúna: EMBRAPA-CNPDA, 1991. 388p. (EMBRAPA-CNPDA. Documentos, 15).

BETTIOL, W. Métodos alternativos para o controle de doenças de plantas In: SAMI, J.M.; BARROS, R. Proteção de plantas na agricultura sustentável Recife : UFRPE, Imprensa Universitária, 368 p. 2001.

BRAGA, M.R. Fitoalexinas. In: PASCHOLATI, S.F.; LEITE, B.; STANGARLIN, J.R.; CIA, P. (Ed.). Interação Planta Patógeno - Fisiologia, bioquímica e biologia molecular. Piracicaba: FEALQ, 2008, p.305-346.

COUTO, M.E. Coleção de plantas medicinais aromáticas e condimentos. Pelotas: Embrapa Clima Temperado. Documentos 157, 2006. 91p.

DE MORAIS, L.A.S. Óleos Essenciais no Controle Fitossanitário In: BETTIOL, W.; MORANDI, M.A.B. Biocontrole de doenças de plantas: uso e perspectivas - Jaguariúna : Embrapa Meio Ambiente. 2009. P.139-152.

BONALDO, S.M.; SOARES, R.N.; SCHWAN-ESTRADA, K.R.F.; STANGARLIN; J.R.; CRUZ, M.E.S. Efeito do óleo essencial de Eucalyptus citriodora e Artemisia camphorata na indução de fitoalexinas em Sorgo e na germinação de Colletotrichum graminicola. In: CONGRESSO BRASILEIRO DE FITOPATOLOGIA, 32, Curitiba, 1999. Resumos. Fitopatologia Brasileira, v.24 (Suplemento), p.268, 1999.

BONALDO, S.M.; SCHWAN-ESTRADA, K.R.F.; STANGARLIN, J.R.; TESSMANN, D.J.; SCAPIM, C.A. Fungitoxicidade, atividade elicitora de fitoalexinas e proteção de pepino contra Colletotrichum lagenarium pelo extrato aquoso de Eucalyptus citriodora. Fitopatologia Brasileira, v.29, p.128-134, 2004.

CAVALCANTI, L.S., BRUNELLI, K.R., STANGARLIN, J.R. Aspectos bioquímicos e moleculares da resistência induzida. In: CAVALCANTI, L.S., DI PIERO, R.M., CIA, P., PASCHOLATI, S.F., RESENDE, M.L.V., ROMEIRO, R.S. (Eds.) Indução de resistência em plantas a patógenos e insetos. Piracicaba SP. FEALQ, 2005. p.81-124.

FARMACOPÉIA Brasileira. 4.ed. São Paulo: Atheneu, 1988.

FRANZENER, G.; S.C. VIGO; STANGARLIN, J.R.; SCHWAN-ESTRADA, K.R.F.; CRUZ, M.E.S.; FURLANETTO, C. Atividades fungitóxicas e elicitora de fitoalexinas no extrato aquoso e tintura vegetal de plantas medicinais. In: CONGRESSO BRASILEIRO DE FITOPATOLOGIA, 33, Belém, 2000. Resumos. Fitopatologia Brasileira, v.25 (Suplemento), p.374, 2000.

FRANZENER, G.; FRANZENER, A.S.M.; STANGARLIN, J.R.; CZEPAK, M.P.; SCHWANESTRADA, K.R.F.; CRUZ, M.E.S. Atividades antibacteriana, antifúngica e indutora de fitoalexinas de hidrolatos de plantas medicinais. Semina. Ciências Agrárias, Londrina/PR, v.28, p. 29-38, 2007.

HAMMERSCHMIDT, H.; DANN, E.K. Induced resistance to disease. In: Rechcigl, N.A. \& Rechcigl, J.E. (Eds.). Environmentally Safe Approaches to Crop Disease Control. Boca Raton: CRC - Lewis Publishers, 1997. Cap.8:177-199.

HAMMERSCHMIDT, R. Phytoalexins: What have we learned after 60 years? Annual Review Phytopathology, Palo Alto, v.37, p.285-306, 1999.

LO, C.L.; WEIERGANG, I; BONHAM, C.; HIPSKIND, J; WOOD, K.; NICHOLSON, R.L. Phytoalexin accumulation in sorghum: identification of methyl ether of lutheolinidin. Physiological and Molecular Plant Pathology, v.49, p.21-31. 1996

LORENZI, H.; MATOS, F.J. de A. Plantas medicinais no Brasil: nativas e exóticas. $2^{\circ}$ edição. Nova Odessa, SP: Instituto Plantarum, 2008. 576p.

MAZARO, S.M.; CITADIN, I.; GOUVÊA, A.DE; LUCKMANN, D.; GUIMARÃES, S.S. Indução de fitoalexinas em cotilédones de Soja em resposta a derivados de folhas de pitangueira. Ciência Rural, Santa Maria, v.38, p.1824-1829. 2008.

MARTINS, E.R.; CASTRO, D.M.; CASTELLANI, D.C.; DIAS, J.E. Plantas medicinais. Viçosa: UFV, p. 3050, 2003.

MEINERZ, C.C.; FORMIGHIERI, A.P.; SCHWANESTRADA, K.R.F.; DIETERICH, C.; FRANZENER, G.; STANGARLIN, J.R. Atividade elicitora de fitoalexinas em Sorgo e Soja por derivados de avenca (Adiantum capillus-veneris L.). Revista Brasileira de Plantas Medicinais, v.10, p.26-31, 2008.

NICHOLSON, R.L., JAMIL, F.F., SNYDER, B.A., LUE, W.L.; HISPKIND, J. Phytoalexin synthesis in the juvenile sorghum leaf. Physiological and Molecular Plant Pathology, v.33, p.271-278. 1988.

OLIVEIRA, J.S.B., CARRARA, A.F., TEMPORAL, W.M., SCHWAN-ESTRADA, K.R.F. Tinturas e óleos essenciais na indução de fitoalexina em hipocótilos de feijão (Phaseolus vulgaris L.). In: CONGRESSO BRASILEIRO DE FITOPATOLOGIA, 43, Cuiabá, 2010. Resumos. Fitopatologia Brasileira, v.35 (Suplemento) p.S33, 2010.

PASCHOLATI, S.F. Potencial de Saccharomyces cerevisiae e outros agentes bióticos na proteção de plantas contra patógenos. Piracicaba, 1998. 123p. Tese (Livre Docência) - Escola Superior de Agricultura "Luiz de Queiroz", Universidade de São Paulo.

PURKAYASTHA, R.P. Progress in phytoalexin research during the past years. In: DANIEL, M.; PURKAYASTHA, R.P. (Ed.). Handbook of Phytoalexin Metabolism And Action. New Yrk: Marcel Dekker, 1995, p.1-39.

RODRIGUES, E.; SCHWAN-ESTRADA, K.R.F.; STANGARLIN, J.R.; CRUZ, M.E.S.; FIORI-TUTIDA, A.C.G. Avaliação da atividade antifúngica de extratos de gengibre e eucalipto in vitro e em fibras de 
bananeira infectadas com Helminthosporium sp. Acta Scientiarum. Agronomy. v.28, p.123-127, 2006.

RODRIGUES, E.; SCHWANESTRADA, K.R.F.; FIORI, A.C.G.; STANGARLIN, J.R.; CRUZ, M.E.S. Fungitoxicidade, atividade elicitora de fitoalexinas e proteção de alface em sistema de cultivo orgânico contra Sclerotinia sclerotiorum pelo extrato de gengibre. Summa Phytopathologica, Botucatu/SP, v.33, p.124128, 2007.

SCHWAN-ESTRADA, K.R.F.; STANGARLIN,J.R.; CRUZ,M.E. da S. Uso de extratos vegetais no controle de fungos fitopatogênicos. Floresta, v.30, p.129-137, 2000.

SCHWANESTRADA, K.R.F; CARVALHO, J.B.; BONALDO, S.M.; CRUZ, M.E.S.; CARLOS, M.M.; STANGARLIN, J.R. Fungitoxicidade de Cymbopogon citratus e Cymbopogon martinii a Colletotrichum gloeosporioides em frutos de pimentão. Revista Brasileira de Plantas Medicinais, v.10, p.88-93, 2008.

SOARES, R.N.; SCHWAN-ESTRADA, K.R.F.; CRUZ, M.E.S.; STANGARLIN, J.R. Potencial de Artemisia camphorata (cânfora) no controle de fungo fitopatogênicos. In: CONGRESSO BRASILEIRO DE FITOPATOLOGIA, 31, Fortaleza, 1998. Resumos.
Fitopatologia Brasileira, v.23 (Suplemento), p.284, 1998. STANGARLIN, J.R.; SCHWAN-ESTRADA, K.R.F.; CRUZ, M.E.S.; NOZAKI, M.H. Plantas medicinais e controle alternativo de fitopatogenos. Biotecnologia Ciência \& Desenvolvimento, Brasília, v.2, p.16-21. 1999.

TAIZ, L.; ZEIGER, E. Fisiologia Vegetal. $3^{a}$ Ed. Porto Alegre. Ed. Artmed. 2004.

TALAMINI, V.; STADNIK, M.J Extratos vegetais e de algas no controle de doenças de plantas. In: STADINIK, M.J.; TALAMINI, V. (Eds.) Manejo ecológico de doenças de plantas, Florianópolis, SC: CCA/UFSC, 2004. p.45-62.

VAN LOON, L.C.; BAKKER, P.A.H.M.; PITERSE, C.M.J. Systemic resistance induced by rhizosphere bacteria. Annual Reviem of Phytopathology, v.36, p.453-483. 1998.

WULFF, N.A.; PASCHOLATI, S.F. Caracterização parcial de elicitores de fitoalexinas em Sorgo isolados de Saccharomyces cerevisiae. Fitopatologia Brasileira, v.24, p.428-435. 1999.

ZIEGLER, E.; PONTZEN, R. Specific inhibition of glucanelicited glyceolin accumulation in soybeans by extracellular mannan-glycoprotein of Phytophthora megasperma f.sp. glycinea. Physiological Plant Pathology, v.20, p.321-331. 1982. 